\title{
Generation of Human iPSC-Derived Myotubes to Investigate RNA-Based Therapies In Vitro
}

\author{
Pablo Herrero-Hernandez, Atze J. Bergsma, and W. W. M. Pim Pijnappel
}

\begin{abstract}
Alternative pre-mRNA splicing can be cell-type specific and results in the generation of different protein isoforms from a single gene. Deregulation of canonical pre-mRNA splicing by disease-associated variants can result in genetic disorders. Antisense oligonucleotides (AONs) offer an attractive solution to modulate endogenous gene expression through alteration of pre-mRNA splicing events. Relevant in vitro models are crucial for appropriate evaluation of splicing modifying drugs. In this chapter, we describe how to investigate the splicing modulating activity of AONs in an in vitro skeletal muscle model, applied to Pompe disease. We also provide a detailed description of methods to visualize and analyze gene expression in differentiated skeletal muscle cells for the analysis of muscle differentiation and splicing outcome. The methodology described here is relevant to develop treatment options using AONs for other genetic muscle diseases as well, including Duchenne muscular dystrophy, myotonic dystrophy, and facioscapulohumeral muscular dystrophy.
\end{abstract}

Key words Splicing, Human iPSC, Skeletal muscle, Antisense oligonucleotides, In vitro models

1 Introduction

Pre-mRNA splicing is a highly conserved process in eukaryotes that plays a role in pre-mRNA processing. Alternative splicing can diversify gene function to produce isoforms with specific functions in distinct cell types $[1,2]$. Genetic variations can lead to defects in pre-mRNA splicing that cause human disease [3]. Modulation of pre-mRNA splicing can be directed to correct aberrant splicing, to skip protein coding variants, to restore the reading frame, or to prevent expression of toxic gene products. This is possible by targeting antisense oligonucleotides (AONs) toward canonical splice sites or to cis-acting regulatory elements such as cryptic splice sites or splicing silencers/enhancers [4]. Alternative splicing in skeletal muscle is abundant and essential for muscle development and function [5]. Deregulation of pre-mRNA splicing in skeletal muscle is known to be the underlying cause of multiple human 
myopathies [5]. Suitable in vitro and in vivo models are crucial to investigate novel splicing modulating drugs in target cells and tissues.

In vitro human skeletal muscle models can be obtained directly from muscle biopsies, or these can be generated by (trans-)differentiation of primary fibroblasts, pluripotent stem cells, or non-muscle cells with myogenic capacity like pericytes and mesoangioblasts [6-8]. Several protocols have been described to generate muscle progenitor cells (MPCs) derived from human patientderived induced pluripotent stem cells (hiPSCs) using directed differentiation methods for disease modeling [9-11].

Here we describe how purified, expandable hiPSC-derived MPCs, generated using a transgene-free procedure [11] can be differentiated into multinucleated myotubes to test the modulating activity of AONs. These methods can be used to analyze splicing correction in vitro to develop RNA-based therapies for muscle disorders. We have used this strategy to test AONs for Pompe disease [12] and describe the methodology here in detail.

\section{Materials}

All cell culture work needs to be performed under sterile conditions in safety cabinets. All cell lines should be tested for mycoplasma following the manufacturer instructions (Lonza; LT07-318). Cell lines are cultured at $5 \% \mathrm{CO}_{2}$ and $37{ }^{\circ} \mathrm{C}$ in humidified incubators.

\subsection{Skeletal Muscle Progenitor Cell Culture}

1. Human MPC lines (see Note 1).

2. DMEM $4.5 \mathrm{~g} / \mathrm{L}$ Glucose.

3. Fetal Bovine Serum.

4. Penicillin/Streptomycin/Glutamine $100 \times(\mathrm{p} / \mathrm{s} / \mathrm{g})$.

5. Fibroblast Growth Factor 2 (FGF2) (see Note 2).

6. Sterile cell culture grade Bovine Serum Albumin (7.5\% BSA).

7. TrypLEтм Express Enzyme $(1 \times)$, phenol red.

8. Phosphate Buffered Saline (DPBS).

9. Extracellular Matrix gel from Engelbreth $(\mathrm{ECM} ; \mathrm{l} \times)$.

10. DMEM:F12.

11. Insulin/Transferrin/Selenium $100 \times$.

12. DMSO.

13. Freezing containers.

2.2 Cell Culture Media
1. Proliferation medium: DMEM $4.5 \mathrm{~g} / \mathrm{L}$ Glucose, supplemented with $10 \% \mathrm{FBS}, 1 \times \mathrm{Pen} /$ Strep, and $100 \mathrm{ng} / \mathrm{ml} \mathrm{FGF2}$ (added directly to plate/well). 


\subsection{Antisense Oligonucleotide Design and Delivery}

\section{4}

Immunofluorescence

2.5 RNA Isolation, cDNA Synthesis, and Quantitative RT-PCR (RT-qPCR)
2. Differentiation medium: DMEM:F12, supplemented with $1 \times$ ITS-X and $1 \times$ Pen/Strep.

1. Phosphorodiamidate morpholino oligomer (PMO) AONs (Gene Tools, LLC.)

2. Endoporter (Gene Tools, LLC.)

3. MilliQ filtered sterile water.

1. 4\% Paraformaldehyde (diluted from a 32\% solution in PBS).

2. $0.1 \%$ Tween (diluted in PBS from a $100 \%$ solution).

3. $0.3 \%$ Triton-X100 (diluted in PBS from a $100 \%$ solution).

4. Bovine Serum Albumin (BSA).

5. Primary antibodies: Mouse- $\alpha$-MYH1E (1:50, MF20 supernatant, DSHB), Rabbit- $\alpha$-MYOGENIN (1:100, sc-576, Santa Cruz), Rabbit- $\alpha$-MYOD (1:100, sc-304, Santa Cruz), Mouse- $\alpha$-PAX7 (1:100, concentrate, DSHB).

6. Secondary antibodies: Horse- $\alpha$-mouse biotin (1:250, Vector Laboratories), Alexa Fluor-594-a-goat, Alexa Fluor488- $\alpha$-mouse, Alexa Fluor-594- $\alpha$-rabbit, Alexa Fluor488- $\alpha$-rabbit (1:500, Invitrogen).

7. Tertiary: Streptavidin 594 (1:500, Invitrogen, S-32356).

8. Hoechst 33342 (1:15,000, Invitrogen, H3570).

9. Nikon wide field microscope ( $10 \times$ and $20 \times$ objectives $)$.

1. RNA isolation kit.

2. cDNA Synthesis kit.

3. iTaq Universal SYBR Green Supermix.

4. Hard-Shell 96-Well PCR Plates.

5. Thermocycler.

6. Real-time thermocycler.

7. Spectrophotometer.

8. Agarose.

9. Ethidium Bromide.

10. Primers (see Table 1). 
Table 1

Primers used for RT-qPCR

\begin{tabular}{ll}
\hline Primer target & Sequence $\left(\mathbf{5}^{\prime}\right.$ to $\left.\mathbf{3}^{\prime}\right)$ \\
\hline$M Y O D \mathrm{fw}$ & CACTCCGGTCCCAAATGTAG \\
$M Y O D \mathrm{rv}$ & TTCCCTGTAGCACCACACAC \\
$M Y O G \mathrm{fw}$ & CACTCCCTCACCTCCATCGT \\
$M Y O G \mathrm{rv}$ & CATCTGGGAAGGCCACAGA \\
\hline$A M P 1 \mathrm{fw}$ & GTGTTAGTGGCACCCAGGTC \\
$L A M P 1 \mathrm{rv}$ & GGAAGGCCTGTCTTGTTCAC \\
$L A M P 2 \mathrm{fw}$ & CCTGGATTGCGAATTTTACC \\
\hline$A M P 2 \mathrm{rv}$ & ATGGAATTCTGATGGCCAAA \\
\hline
\end{tabular}

\section{Methods}

\subsection{Expansion, Cryopreservation, and Differentiation of MPCs}

\subsubsection{Expansion}

1. MPCs grow optimally when the confluency is between 30 and $90 \%$. It is important to maintain this cell density throughout the expansion ( see Note 3 ).

2. Plate cells onto ECM coated plates (see Note 4). Coat plates using a solution of ECM (1:200) diluted in Proliferation medium without FGF2. Coating solution is left on the plates for $30 \mathrm{~min}$ at $\mathrm{RT}$.

3. For cell detachment, first wash plates in pre-warmed PBS at $37^{\circ} \mathrm{C}$ and then treat the cells with a 1:1 pre-warmed solution of TrypLE ${ }^{\mathrm{TM}}$ Express Enzyme and PBS (3 $\mathrm{ml}$ for $10 \mathrm{~cm}$ plates) for $3-5$ min at $37^{\circ} \mathrm{C}$.

4. Collect cells using 5 volumes of Proliferation medium and centrifuge for $4 \mathrm{~min}$ at $200 \times \mathfrak{g}$.

5. Resuspend cells using Proliferation medium, transfer to pre-coated plates (remove coating solution, do not wash), and add $100 \mathrm{ng} / \mathrm{ml}$ of FGF2 directly into the plate (see Note $5)$.

6. Immediately transfer plates to a humidified incubator and perform cross movements to ensure appropriate cell spreading and mixing of FGF2.

1. Thaw vials of MPCs in a pre-warmed water bath, transfer cell suspension slowly into 5 volumes of Proliferation medium (no FGF2), and centrifuge for $4 \mathrm{~min}$ at $200 \times \mathfrak{g}$.

2. Plate cells in pre-coated plates using Proliferation medium plus $100 \mathrm{ng} / \mathrm{ml}$ of FGF2 freshly added to the cells. 
3.1.3 Differentiation into Multinucleated Myotubes

\subsection{Delivery and Efficacy of Antisense Oligonucleotides in Patient-Derived Myotubes}

3.2.1 Transfection

3.2.2

Immunofluorescence
3. Freeze cells using Proliferation medium (plus $100 \mathrm{ng} / \mathrm{ml}$ FGF2) and $10 \%$ DMSO in $1 \mathrm{ml}$ cryovials and store in freezing containers at $-80{ }^{\circ} \mathrm{C}$ for $24 \mathrm{~h}$ (at least) prior to long-term storage in liquid nitrogen tanks.

1. Grow cells to reach $>90 \%$ confluency (avoid $100 \%$ confluency) and then switch to Differentiation medium for 4 days without refreshing (see Note 6). Wide field images of differentiated myotubes are shown in Fig. 1.

1. Resuspend the PMO AONs in RNAse-free MilliQ at a concentration of $1 \mathrm{mM}$.

2. Add $4.5 \mu \mathrm{l}$ of Endoporter reagent per $\mathrm{ml}$ of medium directly to the cells and mix by gentle shaking ( see Note 7).

3. Add the desired amount of PMO AONs to the cells and mix by gentle shaking.

4. Transfect AONs 1 day prior differentiation (day -1$)$. Cells should be $60-80 \%$ confluent.

5. Switch to differentiation medium (day 0 ).

6. Leave cells to differentiate for 4 days and either collect protein or RNA or fix cells for immunofluorescence.

1. For immunofluorescence analysis of patient-derived myotubes, prepare cells using 48-well plates.

2. Wash cells once in PBS.

3. Fix cells using 4\% PFA in PBS for $10 \mathrm{~min}$ at RT, remove and add PBS. Cells can be stored at $4{ }^{\circ} \mathrm{C}$ before proceeding.

4. Wash twice in PBS for 2 min each.

5. Incubate for $10 \mathrm{~min}$ with $0.3 \%$ Triton-X100 in PBS for permeabilization.

6. Incubate for $30 \mathrm{~min}$ with $3 \%$ BSA, $0.1 \%$ Tween in PBS for blocking.

7. Repeat washing step 4.

8. Incubate with primary antibodies for $1 \mathrm{~h}$ at RT in $0.1 \% \mathrm{BSA}$, $0.1 \%$ Tween in PBS (see Note 8 ).

9. Repeat washing step 4.

10. Incubate with secondary antibodies for $45 \mathrm{~min}$ at RT in $0.1 \%$ BSA, 0.1\% Tween in PBS.

11. Repeat washing step 4.

12. If biotinylated antibodies were used, incubate with tertiary for $30 \mathrm{~min}$ at $\mathrm{RT}$ in $0.1 \% \mathrm{BSA}, 0.1 \%$ Tween in PBS.

13. Repeat washing step 4. 

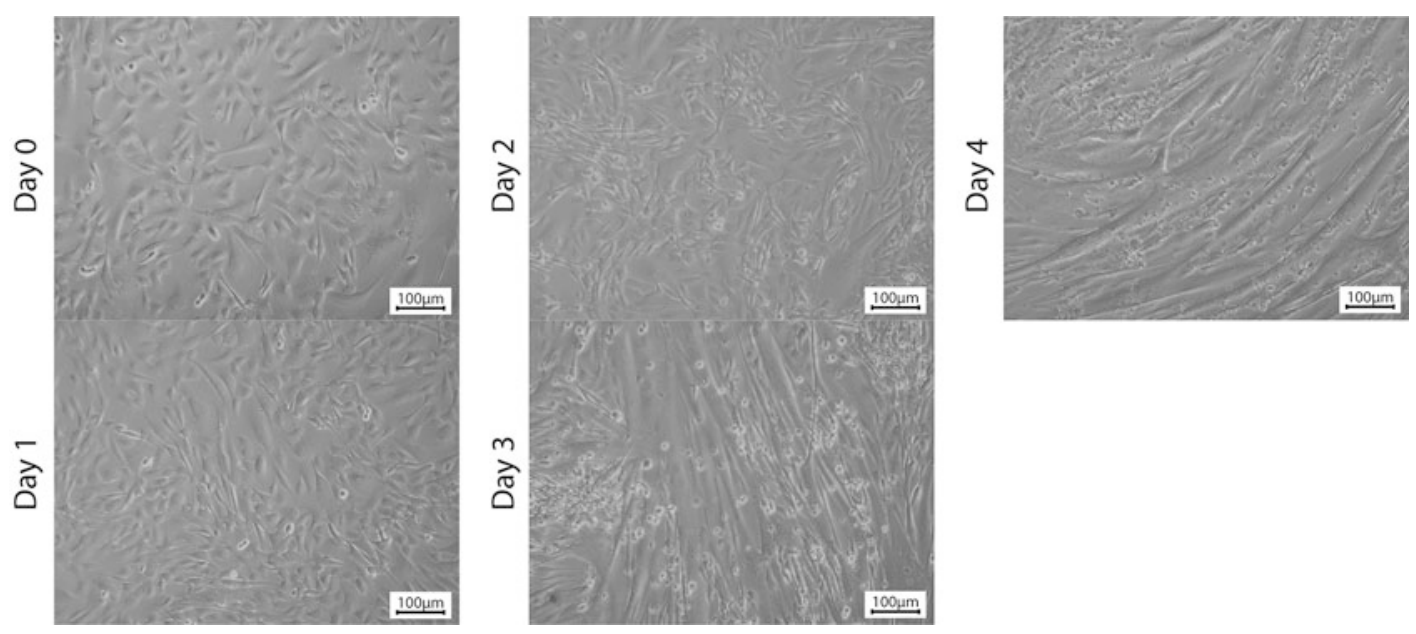

Fig. 1 Wide field images of differentiating MPCs. Representative images of the differentiation of MPCs over 4 days. Scale bar $100 \mu \mathrm{m}$
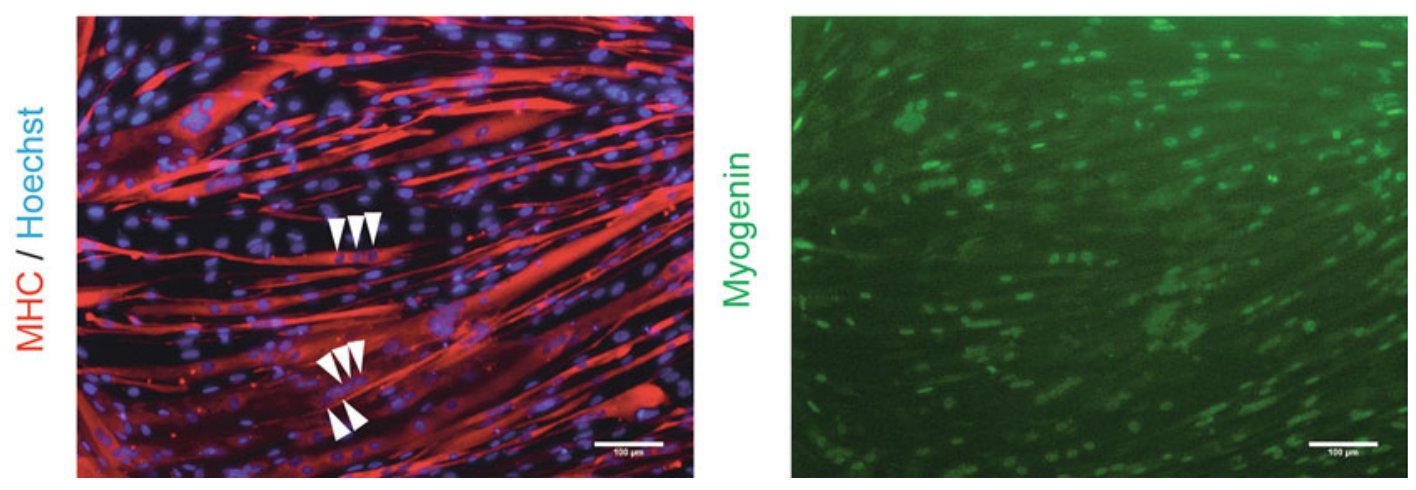

Fig. 2 Immunofluorescence images of 4 days differentiated MPCs. MPCs were stained with MYH1E (red), MYOGENIN (green), and the nuclei with Hoechst (blue). Arrowheads indicate nuclei present in multinucleated myotubes. Scale bar $100 \mu \mathrm{m}$

14. Counterstain with Hoechst nuclear staining $(1: 15,000)$ in PBS for $10 \mathrm{~min}$.

15. Remove and add PBS.

16. Take images of five random fields with $10 \times$ or $20 \times$ lens in MYH1E-stained myotubes (see Fig. 2) to calculate the fusion index. The fusion index is determined as the percentage of nuclei present in multinucleated MYHlE-positive cells $(>2$ nuclei in one cell) with respect to the total number of nuclei.

3.2.3 RT- $R P C R$

1. Harvest RNA after 4 days of differentiation using $350 \mu$ of the lysis buffer (or the amount indicated in the first step of the RNA isolation kit) per well of a 12 well-plate. 
2. Purify RNA following the instructions of the preferred RNA isolation kit.

3. Retrotranscribe $\mathbf{3 0 0 - 5 0 0 ~ n g ~ o f ~ t o t a l ~ R N A ~ i n t o ~ c D N A ~ u s i n g ~ a ~}$ cDNA Synthesis Kit.

4. Dilute cDNA samples $10 \times$ and prepare the qPCR using iTaq Universal SYBR Green Supermix.

5. Amplify the cDNA of interest using a Real Time System.

6. To analyze alternative splice variants in patient-derived myotubes, we normalize gene expression using each of the following four genes: MYOD, MYOG (Myogenin), LAMPl, and LAMP2 (see Note 9). Gene expression is calculated using the $\Delta \mathrm{Ct}$ method for each housekeeping gene. Thereafter, the average value of the four normalized expression values is calculated.

1. Here we only used transgene-free derived muscle progenitor cells from hiPSCs as described in [11]. However, we anticipate that other sources of myogenic cells would also be applicable.

2. The FGF2 stock powder is dissolved in 0.1\% BSA (sterile cell culture-grade BSA diluted in PBS and filtered using a $0.22-\mu \mathrm{m}$ filter) and aliquoted using tips and tubes that were coated with $0.2 \%$ BSA in PBS. The dissolved FGF2 can be stored at $-80{ }^{\circ} \mathrm{C}$. Each aliquot is used for maximally $\mathrm{l}$ week after thawing (kept at $4{ }^{\circ} \mathrm{C}$ ) and $100 \mathrm{ng} / \mathrm{ml}$ is added directly to the cell culture medium every 2 days. When adding FGF 2 every 2 days, this can be done without refreshing cell culture media. However, cell culture media must be refreshed every 3 days.

3. MPCs spontaneously differentiate at a confluency of $>90 \%$ and loose proliferative capacity in culture.

4. Here we only used ECM for our studies. However, we anticipate that other coating materials can be used as well.

5. We typically plate a $1 / 4$ or $1 / 6$ dilution of cells to get a $60-90 \%$ confluency in 2 days and 3 days, respectively, using the same plate surface area.

6. There are different methods to differentiate MPCs into multinucleated myotubes [9-12]. For these studies we used DMEM:F12, $\mathrm{l} \times \mathrm{ITS}-\mathrm{X}, \mathrm{l} \times \mathrm{p} / \mathrm{s} / \mathrm{g}$ for 4 days without refreshing. Longer differentiation periods might result in cell detachment due to spontaneous contraction.

7. Endoporter reagent is specifically designed for transfection of PMO AONs and was used by us in the following studies $[4,11]$. Endoporter reagent does not form a complex with AONs, but it enhances endocytosis in cells. The amount of 
Endoporter used is independent of the concentration of PMO AONs. Other backbones might require different delivery reagents.

8. The following proteins are commonly used to assess myogenic potential of differentiating MPCs across species: Myosin heavy chain (MYHlE, cytoplasmic), Myogenin (MYOG, nuclear), and MYOD (nuclear). PAX7 (nuclear) can be used to identify the muscle stem cell fraction.

9. To normalize gene expression, we observed that the following genes involved in myogenesis: MYOD and MYOG; and the following involved in lysosome biogenesis: $L A M P I$ and $L A M P 2$; do not change expression levels among patient and healthy donor derived myotubes. We used these genes in this study [12].

\section{Acknowledgments}

We thank Erik van der Wal for the critical reading and the revisions of this manuscript. This work was funded by Tex net, the Prinses Beatrix Spierfonds/Stichting Spieren voor Spieren (grant W. ORl3-21), the Sophia Children's Hospital Foundation (SSWO) (grant S-687 and S17-32), and Metakids (grant 2016-063).

\section{References}

1. Shapiro MB, Senapathy P (1987) RNA splice junctions of different classes of eukaryotes: sequence statistics and functional implications in gene expression. Nucleic Acids Res 15(17): 7155-7174. https://doi.org/10.1093/nar/ 15.17 .7155

2. Lei Q, Li C, Zuo Z, Huang C, Cheng H, Zhou $\mathrm{R}$ (2016) Evolutionary insights into RNA trans-splicing in vertebrates. Genome Biol Evol 8(3):562-577. https://doi.org/10. $1093 / \mathrm{gbe} / \mathrm{evw} 025$

3. Bergsma AJ, van der Wal E, Broeders $M$, van der Ploeg AT, Pim Pijnappel WWM (2018) Alternative splicing in genetic diseases: improved diagnosis and novel treatment options. Int Rev Cell Mol Biol 335:85-141. https://doi.org/10.1016/bs.ircmb.2017. 07.008

4. van der Wal E, Bergsma AJ, Pijnenburg JM, van der Ploeg AT, Pijnappel W (2017) Antisense oligonucleotides promote exon inclusion and correct the common c.-32-13T $>$ G GAA splicing variant in Pompe disease. Mol Ther Nucleic Acids 7:90-100. https://doi.org/10. 1016/j.omtn.2017.03.001
5. Pistoni M, Ghigna C, Gabellini D (2010) Alternative splicing and muscular dystrophy. RNA Biol 7(4):441-452. https://doi.org/10. 4161/rna.7.4.12258

6. Baghdadi MB, Tajbakhsh S (2018) Regulation and phylogeny of skeletal muscle regeneration. Dev Biol 433(2):200-209. https://doi.org/ 10.1016/j.ydbio.2017.07.026

7. Ito N, Kii I, Shimizu N, Tanaka H, Takeda S (2017) Direct reprogramming of fibroblasts into skeletal muscle progenitor cells by transcription factors enriched in undifferentiated subpopulation of satellite cells. Sci Rep 7(1): 8097. https://doi.org/10.1038/s41598017-08232-2

8. Selvaraj S, Kyba M, Perlingeiro RCR (2019) Pluripotent stem cell-based therapeutics for muscular dystrophies. Trends Mol Med 25(9): 803-816. https://doi.org/10.1016/j. molmed.2019.07.004

9. Choi IY, Lim H, Estrellas K, Mula J, Cohen TV, Zhang Y, Donnelly CJ, Richard JP, Kim YJ, Kim H, Kazuki Y, Oshimura M, Li HL, Hotta A, Rothstein J, Maragakis N, Wagner KR, Lee G (2016) Concordant but varied 
phenotypes among Duchenne muscular dystrophy patient-specific myoblasts derived using a human iPSC-based model. Cell Rep 15(10):2301-2312. https://doi.org/10. 1016/j.celrep.2016.05.016

10. Hicks MR, Hiserodt J, Paras K, Fujiwara W, Eskin $\mathrm{A}$, Jan $\mathrm{M}$, $\mathrm{Xi} \mathrm{H}$, Young $\mathrm{CS}$, Evseenko D, Nelson SF, Spencer MJ, Handel BV, Pyle AD (2018) ERBB3 and NGFR mark a distinct skeletal muscle progenitor cell in human development and hPSCs. Nat Cell Biol 20(1):46-57. https://doi.org/10.1038/ s41556-017-0010-2

11. van der Wal E, Herrero-Hernandez P, Wan R, Broeders M, In 't Groen SLM, van Gestel TJM, van Ijcken WFJ, Cheung TH, van der Ploeg AT, Schaaf GJ, Pijnappel W (2018) Largescale expansion of human iPSC-derived skeletal muscle cells for disease modeling and cellbased therapeutic strategies. Stem cell Rep 10(6):1975-1990. https://doi.org/10.1016/ j.stemcr.2018.04.002

12. van der Wal E, Bergsma AJ, van Gestel TJM, In 't Groen SLM, Zaehres H, Arauzo-Bravo MJ, Scholer HR, van der Ploeg AT, Pijnappel W (2017) GAA deficiency in Pompe disease is alleviated by exon inclusion in iPSC-derived skeletal muscle cells. Mol Ther Nucleic Acids 7:101-115. https://doi.org/10.1016/j. omtn.2017.03.002

Open Access This chapter is licensed under the terms of the Creative Commons Attribution 4.0 International License (http://creativecommons.org/licenses/by/4.0/), which permits use, sharing, adaptation, distribution and reproduction in any medium or format, as long as you give appropriate credit to the original author(s) and the source, provide a link to the Creative Commons license and indicate if changes were made.

The images or other third party material in this chapter are included in the chapter's Creative Commons license, unless indicated otherwise in a credit line to the material. If material is not included in the chapter's Creative Commons license and your intended use is not permitted by statutory regulation or exceeds the permitted use, you will need to obtain permission directly from the copyright holder. 